\title{
PUBLIC HEALTH DATA
}

\section{Partnering With Communities to Improve Health: The New York City Turning Point Experience}

Eve R. Cagan, Tamara Hubinsky, Andrew Goodman, Deborah Deitcher, and Neal L. Cohen

\begin{abstract}
Concurrent with the New York City Department of Health's reorganization efforts, the Robert Wood Johnson and W.K. Kellogg Foundations launched Turning Point, a national initiative designed to strengthen the nation's public health system. The Turning Point initiative has emphasized broad-based partnership building and planning as key prerequisites for improving public health practice. In response to the foundations' request for proposals, the department formed a New York City Public Health Partnership, which in turn applied for and was granted a Turning Point planning grant. This funding allowed New York City Turning Point to initiate a public health planning process, part of which involved convening forums in each of the five boroughs. With over 1,100 community participants, these forums provided both a starting point for establishing public health priorities and an interactive setting for sharing health and demographic data. Included among the issues that emerged as priorities were: access to care, environmental health, mental health, housing, asthma, education, and dietary issues. Building on the forum outcomes, the New York City Public Health Partnership developed a public health system improvement plan. The goals delineated in this plan are: (1) to create and support public health partnerships at the community, borough, and citywide levels; (2) to identify community health concerns and develop strategies responsive to these concerns; and (3) to develop policies to support and sustain a community health approach to improve health status. This article also discusses possible roles for local health departments in promoting a community health approach to address public health concerns.
\end{abstract}

\section{INTRODUCTION}

New York City is home to the nation's largest municipal public health department, an impressive array of academic medical centers, and some of the nation's leading health care delivery systems. Yet, in spite of the considerable resources devoted to these systems and their many notable accomplishments over the years, New Yorkers still suffer from an unacceptably high burden of illness and injury. Areas of concern include large disparities between rich and poor in many health status indicators; inequalities in access to both medical services and community-based health

\footnotetext{
The authors are from the New York City Department of Health.

Correspondence: Tamara Hubinsky, 125 Worth Street, New York, NY 10013. (E-mail: thubinsk@ HEALTH.GOV.NYC)
} 
promotion and disease prevention programs; insufficient attention to the broad determinants of health, such as education, income, and social status; inadequate mechanisms to engage the community in health planning and action to address priority issues; and the lack of a coordinated, multisector approach to improve the health of New Yorkers.

To address these issues, the New York City Department of Health, like many other local health departments (LHDs) around the country, has been involved in strategic planning and reorganization efforts. These efforts reflect a shift in how community health problems are addressed. The medical model, long relied upon by public health professionals as a key strategy for ensuring the public's health, is now being supplemented by an approach that considers both the broad array of factors (psychosocial, economic, environmental, and others) and the range of strategies that influence health. Such strategies include fostering partnerships with a diverse group of sectors and developing multicomponent interventions that include media, educational, environmental, and policy activities. "No longer should we use the old paradigm, asking what type of care is required to reduce major health problems. Instead, we should ask what action must be taken to solve the major health problems facing a population." $1(\mathrm{p} 559)$

As part of the department's new approach, there is an emphasis on working more closely with communities to set priorities, to develop programs and policies to address them, and to foster coordination among the department's many programs, other city agencies, and the private sector. To support this work, a new division, Community HealthWorks, has been established to provide technical assistance to community organizations, city agency staff, and leadership, business, health care partners, as well as others in designing and launching community health initiatives.

Concurrent with the Department of Health's reorganization efforts, the Robert Wood Johnson and W.K. Kellogg Foundations launched Turning Point, a national initiative designed to strengthen the nation's public health system. The Turning Point initiative has emphasized broad-based partnership building and planning as key prerequisites for improving public health practice. In response to the foundations' request for proposals, the department formed a New York City Public Health Partnership, which in turn applied for and was granted a Turning Point planning grant. The New York City Turning Point experience and, relatedly, the Department of Health's efforts to create an agency infrastructure to support Turning Point and other community health activities are described below.

\section{NEW YORK CITY TURNING POINT}

New York City Turning Point is a citywide planning project aimed at strengthening the city's public health system. By public health system, we mean a broad array of activities that require the participation of numerous sectors and disciplines to address the many factors that contribute to the health of a community. This definition, while acknowledging the roles assumed by the municipal hospital system and local government, also incorporates the work of many others, including the academic, housing, and business sectors.

Over the past 3 years, Turning Point has established a citywide partnership and five regional, or borough, planning committees; organized community forums to gather opinions and perspectives on the health of the city; and developed a New 
York City Public Health Agenda. The project recently was awarded a Turning Point National Achievement Award from the National Association of County and City Health Officials and the Kellogg Foundation in recognition of its accomplishments.

The guiding body for Turning Point has been the New York City Public Health Partnership, a broad-based group of institutions and individuals with a common interest in improving community health. Members include health care providers, social service providers, academic institutions, governmental agencies, communitybased organizations, and others; among the members are organizations that represent a citywide constituency and some that represent smaller, borough- or community-specific constituencies. Community HealthWorks convenes the partnership and coordinates and staffs the project's activities.

Early in its tenure, the partnership decided that, to conduct a public health planning process in a city as large and complex as New York, borough-level activities organized by regional planning committees would provide an organizational structure that increased the opportunity for community involvement. Community health forums were held in all five boroughs, providing a starting point for establishing public health priorities and an interactive setting for sharing health and demographic data. Each forum consisted of a plenary session in which the importance of the community's role in the work of public health was highlighted, and an overview of key data was provided. Following this general session, participants reconvened in work groups, organized by geographic region, to share their perspectives on the public health challenges faced by the communities in which they reside and/or work.

Over 1,100 community members attended the five forums. In work group discussions, participants brainstormed about health concerns, set public health priorities, and identified neighborhood assets that could be used to address these concerns. Included among the issues that emerged as priorities were: access to care, environmental health, mental health, housing, asthma, education, and dietary issues. Additionally, forum participants in each borough identified a wide variety of community assets that could be utilized to improve the health of communities. Some of the assets mentioned by forum attendees included: tenant, business, and block associations; faith communities; libraries; adult education programs; parks and beaches; media support; sports groups and health clubs; college community service programs; community boards; YMCAs; public transportation; police support; and immigrant service organizations.

These forums were planned, marketed, and facilitated by the borough planning committees. Similar to the citywide partnership, each committee includes a diverse range of organizations that represent a variety of sectors and communities in each borough. Members of the borough planning committees are represented on the citywide partnership. A marked expansion in the size of the partnership-from 30 organizations to 300 - can be attributed largely to the inclusion of organizations that participate in the borough planning committees.

At the end of its second year of planning activities, the partnership developed a public health system improvement plan-the New York City Public Health Agenda-that outlines a framework, including goals and related objectives, for achieving Turning Point's vision of creating healthy communities. The goals delineated in the agenda are (1) to create and support public health partnerships at the community, borough, and citywide levels; (2) to identify community health concerns and develop strategies responsive to these concerns; and (3) to develop policies to support and sustain a community health approach to improve health status. 


\section{IMPLICATIONS FOR THE LOCAL HEALTH DEPARTMENT}

As an active partner and convener of this citywide planning process, the Department of Health has assumed a critical role in Turning Point's development. It has promoted the establishment of partnerships as a means of formalizing the involvement of communities in the work of public health. And as a result of this planning process, the department is creating an infrastructure better equipped to support work in the community.

The adoption of this community health approach has several implications for LHDs. First, it is essential that the LHD play a leadership role in articulating a new vision of public health. The LHD needs to communicate what is meant by a "healthy community," identify those who need to be involved in creating one, and guide the process to achieve it. Because of the need to reallocate resources (or obtain new resources), it is critical that the public and policymakers understand and support this strategy to improve health status.

Second, the LHD needs to partner with community groups and other sectors in planning and implementing community health activities. A challenge exists in that the LHD, as facilitator or convener of partnerships, needs to allow the locus of control to shift away from a government-centric model to a community-driven one.

Third, the LHD needs to harness its considerable array of resources (such as data, access to other government agencies and policymakers, funding, program development expertise, and staffing) to support community work. One strategy for harnessing these resources is to create a program within an LHD dedicated to promoting the community health approach through the provision of technical assistance; at the New York City Department of Health, Community HealthWorks was created for this purpose.

An example of another strategy for resource coordination can be seen in the preparation of health profiles distributed at Turning Point's community health forums. Drawing on the data collection and analysis resources of various parts of the agency, a profile for each borough was developed that contained select demographic and health data for each community housed within that borough. These profiles allowed for a more informed discussion of borough- and community-specific public health issues.

\section{FUTURE DIRECTIONS FOR COLLECTIVE ACTION: THE NEW YORK CITY PUBLIC HEALTH PARTNERSHIP}

The Turning Point planning process has provided a foundation on which the Public Health Agenda can be launched. The department and its partners are learning to work collaboratively, rather than independently, building on each other's strengths. There is now greater appreciation for an integrated approach to public health issues. For example, children's advocates are recognizing the value of working with urban planners to improve the health of the city's children. In addition, the partnership is considering multiple strategies for effecting change; not just relying on service delivery, partners are recognizing the value of capacity building and policy development as equally effective vehicles for improving health.

The New York City Public Health Partnership is now poised to make operational its Public Health Agenda. Policy development is one component of this agenda and provides an example of how we might move forward. Suppose a 
healthy city policy platform is developed and supported by the partnership. This platform might include an objective related to increased opportunities for physical activity among children in New York City. Partners could promote this objective in various ways, depending on their specific interests and expertise. An after school program might survey a community for possible sites to locate recreational spaces, while the Department of Health might coordinate efforts of relevant government agencies (for example, Departments of Parks and Recreation, Sanitation, Board of Education) that could help realize this objective.

Other considerations relate to the provision of technical assistance to the borough planning committees as they undertake activities in support of this objective. One would not need to look much further than the membership of these committees and the citywide partnership to find a variety of expertise. An academic institution could provide training in conducting community surveys to ascertain residents' desires and concerns related to recreational opportunities. The Department of Health could organize workshops for partners and other community residents on the growing concern about childhood obesity and its relationship to physical inactivity.

Yet another component of a healthy city project might be the development of a New York City Community Health Leadership Network. This would include a full menu of activities and tools to support healthy city activities. The Department of Health, through its Web site, could offer community health profiles that would include information on the availability of children's recreational facilities; a description of a model program in New York City or elsewhere that had improved recreation options for children; and a moderated discussion group for organizations concerned with these issues.

The New York City Public Health Partnership will use its National Turning Point Achievement Award to leverage support for its continued work. This work, as illustrated above, would foster a public health constituency and leadership for long-term support of a healthy city.

\section{REFERENCE}

1. Lamarche PA. Public Health Rep. 1995;110(5):556-560 [discussion 555, 561]. 